\title{
Under the Knife
}

Bright, white fluorescent

lights

chill

the never-ending corridor.

A breeze

flows

through

the stark, dry air.

Cold

bleached sheets

wrap my chilled body.

If I were not so frightened,

I would surely sleep.

A needle sticks.

The prickly burn

flows through me

and warms me

if only for a moment.

Voices murmur

beyond my reach.

I scratch my cold face,

yet can hardly feel it.

Are you ready?'

The bed slowly rolls into

a pine-scented room.

Monitors beep.

I hear my heartbeat

from the monitor

and from inside. 
Shiny, white metal lights

glow over me,

surround me.

The cold, rubber mask

swallows my face.

A sickening sweetness

fills my mouth

and nose.

'Count backwards.'

Fifty, forty-nine, forty-eight ...

Too tired to

cry,

speak.

Too scared to

sleep.

The light becomes brighter.

The voices echo

louder.

My heart pounds

harder.

A black shade

falls over my eyes

and mind.

A final thought comes to me:

I hope that monitor doesn’t stop beeping.

Kori Gerland, Northbrook Senior High

Kori Gerland is 18 years of age and has just graduated from high scool. In her brief lifetime, she has undergone multiple surgical procedures for a spinal cord astrocytoma and she has been paraplegic for many years. Despite all of the hardships she has experienced, she has always been 'upbeat' and is pursuing life and all that it offers with both vigor and optimism. 


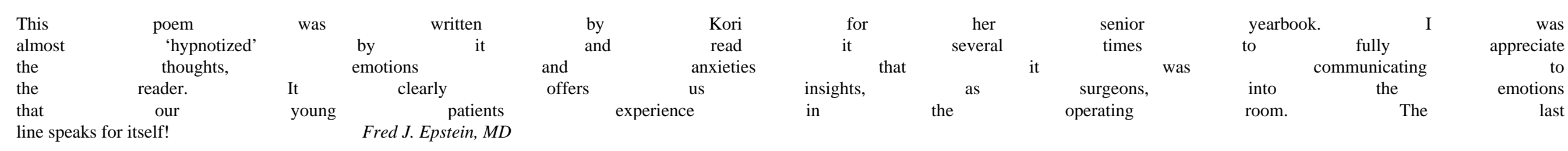

